\title{
Consideration of limitations in the form of inequalities in optimal planning of power systems regimes under uncertainty initial information
}

\author{
Sh.Sh.Latipov ${ }^{1, *}$, A.E. Shanazarov ${ }^{1}$, I.B. Ikramdjanov ${ }^{1}$ \\ ${ }^{1}$ Tashkent State Technical University named after Islam Karimov, Uzbekistan, Department of Power engineering
}

\begin{abstract}
In the article the issues of taking into account of constraints in the form of inequality in optimal planning of short-term modes of power systems are considered. An efficient algorithm for solving of the problem is offered. On the basis of computational experiments for specific problems of optimal planning of modes of power systems the efficiency of the proposed algorithm is revealed.
\end{abstract}

Keywords. Optimization, constraint, target function, information, indefinite information, optimal planning.

The problem of optimal planning of short-term modes of large power systems is a complex problem that uses various forms of initial information. At the same time, a distinction is made between deterministic, probabilistic and uncertain initial information. Deterministic information gives a fairly complete picture for solving the considered problem of the state of the event. The probabilistic information specifies information about the possible random states of the event with the corresponding probabilities of their occurrence.

Uncertainty means that this information associates a given state of an event not with a point, but with a certain domain of definition in the state space. Within this area, the state is not defined as either deterministic or probabilistic. In addition, the boundaries of this area turn out to be "blurred or vague", which cannot be clearly fixed. As a result, the state of an event can be judged only with a certain error determined by these boundaries of the state region. Uncertainty does not mean the fundamental impossibility of representing the event that it reflects. It is a consequence of two circumstances: the incompleteness of the information received and errors in the formation, transmission, reception and processing of information.

Currently, the methods and algorithms for optimal planning of short-term modes of power systems with deterministic initial information are quite perfect $[1, \mathrm{p}$. $329-375 ; 3$, p. $23-62 ; 5$, p. 86-168; 6, p. 11-69]. At the same time, such a conclusion cannot be made for similar problems with various constraints in the form of inequalities under conditions of probability and, especially, uncertainty of the initial information. In this regard, research works aimed at improving existing and developing new methods and algorithms for optimization, taking into account operating and technological constraints in the form of inequalities in conditions of probability and uncertainty of the initial information, are relevant.

In this paper, we propose an algorithm for optimizing the modes of power systems taking into account constraints in the form of inequalities under conditions of partial uncertainty of the initial information. When describing the essence of the algorithm, for convenience, we will consider an energy system in which only thermal power plants (TPP) participate in optimization.

In the known range of the initial parameter, its $n$ values $P_{l}, P_{2}, \ldots, P_{n}$ are taken at approximately the same intervals. Then, taking in turn each of the accepted values of the initial parameter as deterministic, the deterministic optimization problem is solved taking into account all constraints, including constraints in the form of inequalities as in $[2$, p. 40-41; 4, p. 60]. As a result, conditionally optimal solutions (plans) of the problem $U_{l}$, $U_{2}, \ldots, U_{n}$ are obtained. For all obtained conditionally optimal plans $U_{i}$ and possible values of the initial parameter $P_{j}$, the values of the objective function $F_{i j}=F$ $\left(U_{i}, P_{j}\right)$ are calculated, according to which the "payment matrix" is formed.

In the optimization calculation according to this algorithm, simple constraints imposed on the independent variables (controlled parameters) of the problem

$U_{i}^{\min } \leq U_{i} \leq U_{i}^{\max }, \quad i=1,2, \ldots, n$

are taken into account automatically when solving deterministic optimization problems. A functional limitation in the form of equality in the balance of active power in the power system

$$
\sum_{i=0}^{N} P_{i}=P_{H}
$$

is taken into account by the introduction of a balancing station, defining its capacity as

\footnotetext{
*Corresponding author: sherkhonlatipov@gmail.com
} 


$$
P_{0}=P_{H}-\sum_{i=1}^{N} P_{i}
$$

where $\mathrm{N}$ is the number of TPPs involved in optimization (except for balancing TPP); - total load of the power system; $P_{i}$ is the power of the $i-t h$ TPP.

Consideration of restrictions in the form of inequalities, for example, on the maximum permissible values of power flows through controlled power transmission lines (PTL)

$$
P_{l} \leq P_{l}^{\max }, \quad l=1,2, \ldots, L
$$

provides for the use of $L$ pay matrices, the elements of which are defined as

$$
P_{l i j}=P_{l}\left(U_{i}, P_{j}\right) \text {. }
$$

After the formation of the payment matrix, consisting of the values of the objective function and L payment matrices with the values of the power flows through the controlled transmission lines, from the total number of conditionally optimal plans, only admissible conditionally optimal plans are allocated for which all constraints are fulfilled. To this end, those conditionally optimal designs $U_{i}$ are discarded from the total number for which constraint (4) is not satisfied for at least one $P_{j}(j=$ $1,2, \ldots, n)$.

The optimal plan is selected from the remaining conditionally optimal plans by the minimax criterion.

The efficiency of the described algorithm is studied using the example of optimal planning of the short-term mode of the power system, the diagram of which is shown in the figure.

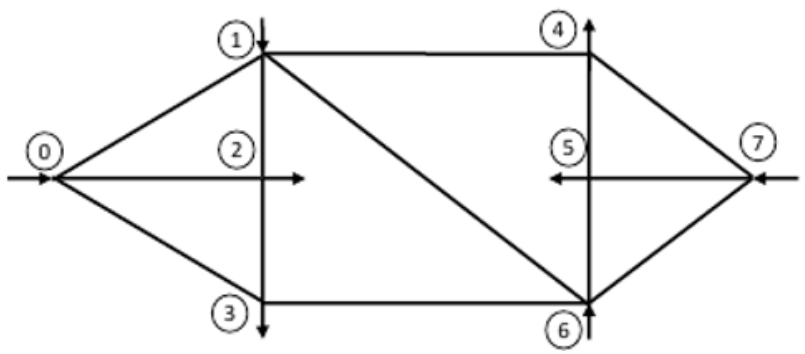

Fig.1. Power system diagram

At nodes $0,1,6$ and 7 there are calculated (participating in optimization) TPPs with the following consumption characteristics of the equivalent fuel, t.o.e $/ \mathrm{h}$ :

$B_{0}=100+0,2 P_{0}+0,002 P_{0}^{2}$,

$B_{1}=120+0,2 P_{1}+0,0025 P_{1}^{2}$,
$B_{6}=60+0,15 P_{6}+0,0015 P_{6}^{2}$,

$B_{7}=80+0,25 P_{7}+0,001 P_{7}^{2}$.

Nodes 2, 3, 4 and 5 are loading with partially undefined loads, the limit values of which are given in Table 1. lines:

Active power flows are monitored for three power

$$
P_{6-3} \leq 470 \mathrm{MW}, \quad P_{6-5} \leq 95 \mathrm{MW}, \quad P_{0-3} \leq 150 \mathrm{MW} .
$$

Power flows through controlled transmission lines are found by the power distribution coefficients of the nodes, which are shown in Table 2.

Table 1. Ultimate loads.

\begin{tabular}{|l|c|c|}
\hline $\begin{array}{l}\text { Limit } \\
\text { load }\end{array}$ & $P^{\min }$ & $P^{\max }$ \\
\hline$P_{L}, \mathrm{MW}$ & 1485 & 1815 \\
\hline$P_{2}, \mathrm{MW}$ & 349 & 427 \\
\hline$P_{3}, \mathrm{MW}$ & 524 & 641 \\
\hline$P_{4}, \mathrm{MW}$ & 175 & 214 \\
\hline$P_{5}, \mathrm{MW}$ & 437 & 533 \\
\hline
\end{tabular}

To solve the problem with the described algorithm, in the given ranges of the initial parameters (node loads), we select 5 values of the loads shown in Table 3 .

Table 3. Possible node loads.

\begin{tabular}{|c|c|c|c|c|c|}
\hline Interval, $i$ & 1 & 2 & 3 & 4 & 5 \\
\hline$P_{H}, \mathrm{MW}$ & 1485 & 1567,5 & 1650 & 1732,5 & 1815 \\
\hline$P_{2}, \mathrm{MW}$ & 349 & 369 & 388 & 408 & 427 \\
\hline$P_{3}, \mathrm{MW}$ & 524 & 527 & 582 & 611 & 641 \\
\hline$P_{4}, \mathrm{MW}$ & 175 & 198 & 194 & 204 & 214 \\
\hline$P_{5}, \mathrm{MW}$ & 437 & 473,5 & 486 & 509,5 & 533 \\
\hline
\end{tabular}

For given loads of nodes (Table 3), the optimization problem was solved five times in a deterministic formulation. At the same time, the objective function was minimized, which is the sum of the equivalent fuel consumption in the calculated TPP B, taking into account the constraints on the condition of the active power balance in the power system and on the power flows in the controlled transmission lines. Based on the results of such optimization, according to the values of the objective function, the payment matrix given in Table 4 was obtained, as well as three payment matrices according to the values of power flows in the Controlled transmission lines.

Table 2. Coefficients of power distribution of nodes by controlled by power lines

\begin{tabular}{|c|c|c|c|c|c|c|c|}
\hline & \multicolumn{9}{|c|}{ Nodes } \\
\cline { 2 - 8 } PTL & 1 & 2 & 3 & 4 & 5 & 6 & 7 \\
\hline $6-3$ & 0,2536 & $-0,0713$ & $-0,0172$ & 0,4106 & 0,489 & 0,6343 & 0,4986 \\
\hline & $-0,0701$ & 0,02025 & 0,0484 & $-0,281$ & 0,4223 & 0,1029 & 0,2986 \\
\hline $6-5$ & $-0,14$ & $-0,1735$ & $-0,267$ & 0,1744 & - & - & - \\
$0-3$ & & & & & - & - \\
\hline
\end{tabular}


Table 4. Payment matrix of objective function values, t.f./h.

\begin{tabular}{|c|c|c|c|c|c|c|}
\hline \multirow[t]{2}{*}{$\begin{array}{l}\text { Number } \\
\text { plan }\end{array}$} & \multirow[t]{2}{*}{$\begin{array}{l}\text { Conditionally } \\
\text { optimal TPP } \\
\text { capacities, MW }\end{array}$} & \multicolumn{5}{|c|}{ Total power system load, MW } \\
\hline & & 1485 & 1567,5 & 1650 & 1732,5 & 1815 \\
\hline 1 & $\begin{array}{l}P_{1}=233 \\
P_{6}=405 \\
P_{7}=556\end{array}$ & $\left(\mathrm{P}_{0}=291\right) 1582,3$ & $\begin{array}{c}\left(\mathrm{P}_{0}=373,5\right) \\
1730,5\end{array}$ & $\begin{array}{c}\left(\mathrm{P}_{0}=456\right) \\
1874,1\end{array}$ & $\begin{array}{c}\left(\mathrm{P}_{0}=538,5\right) \\
2115,3\end{array}$ & $\begin{array}{c}\left(\mathrm{P}_{0}=621\right) \\
2338,9\end{array}$ \\
\hline 2 & $\begin{array}{c}P_{l}=230 \\
P_{6}=382 \\
P_{7}=605,5\end{array}$ & $\begin{array}{c}\left(\mathrm{P}_{0}=267,5\right) \\
1584,1\end{array}$ & $\begin{array}{c}\left(\mathrm{P}_{0}=350\right) \\
1725,6\end{array}$ & $\begin{array}{c}\left(\mathrm{P}_{0}=432,5\right) \\
1870,9\end{array}$ & $\begin{array}{c}\left(\mathrm{P}_{0}=515\right) \\
2114,7\end{array}$ & $\begin{array}{c}\left(\mathrm{P}_{0}=597,5\right) \\
2345,5\end{array}$ \\
\hline 3 & $\begin{array}{l}P_{1}=360 \\
P_{6}=392 \\
P_{7}=600\end{array}$ & $\left(\mathrm{P}_{0}=133\right) 1587,6$ & $\begin{array}{c}\left(\mathrm{P}_{0}=215,5\right) \\
1728,4\end{array}$ & $\begin{array}{c}\left(\mathrm{P}_{0}=298\right) \\
1872,2\end{array}$ & $\begin{array}{c}\left(\mathrm{P}_{0}=380,5\right) \\
2135,3\end{array}$ & $\begin{array}{c}\left(\mathrm{P}_{0}=463\right) \\
2344,4\end{array}$ \\
\hline 4 & $\begin{array}{c}P_{1}=625 \\
P_{6}=250 \\
P_{7}=665,5\end{array}$ & $\begin{array}{c}\left(\mathrm{P}_{0}=-55,5\right) \\
1588,2\end{array}$ & $\begin{array}{c}\left(\mathrm{P}_{0}=27\right) \\
1730,4\end{array}$ & $\begin{array}{c}\left(\mathrm{P}_{0}=109,5\right) \\
1866,5\end{array}$ & $\begin{array}{c}\left(\mathrm{P}_{0}=192\right) \\
2148,4\end{array}$ & $\begin{array}{c}\left(\mathrm{P}_{0}=274,5\right) \\
2322,2\end{array}$ \\
\hline 5 & $\begin{array}{l}P_{I}=247,5 \\
P_{6}=429,6 \\
P_{7}=589,6\end{array}$ & $\begin{array}{c}\left(\mathrm{P}_{0}=-153\right) \\
1577,5\end{array}$ & $\begin{array}{c}\left(\mathrm{P}_{0}=-70,5\right) \\
1744,6\end{array}$ & $\begin{array}{c}\left(\mathrm{P}_{0}=12\right) \\
1830,3\end{array}$ & $\begin{array}{c}\left(\mathrm{P}_{0}=94,5\right) \\
2166,7\end{array}$ & $\begin{array}{c}\left(\mathrm{P}_{0}=177\right) \\
2355,8\end{array}$ \\
\hline
\end{tabular}

Table 5. Cases of violation of restrictions on power flows in controlled power lines.

\begin{tabular}{|l|c|c|}
\hline \multirow{2}{*}{$\begin{array}{l}\text { Number } \\
\text { plan }\end{array}$} & 1485 & \multicolumn{2}{|c|}{ Total power system load, MW } \\
\cline { 2 - 3 } & & $\mathrm{P}_{6-5}=104,8>95, \mathrm{P}_{0-3}=153,5>150$ \\
\hline 1 & $\mathrm{P}_{6-3}=478,3>470$ & \\
\hline 4 & & $\mathrm{P}_{6-3}=479,9>470$ \\
\hline 5 & & \\
\hline
\end{tabular}

As a result of the analysis of payment matrices according to the values of power flows in controlled transmission lines, it was revealed that under certain loads of nodes for conditionally optimal plans 1, 4 and 5, some restrictions are violated (Table 5). Therefore, these conditionally optimal plans are excluded from further consideration.

In accordance with the proposed algorithm, the optimal plan is selected from among the remaining two the 2nd and 3rd conditionally optimal designs according to the minimax criterion. As a result, the third conditionally optimal plan was obtained as the optimal plan, in which

$$
\begin{aligned}
& \min (i) \max (j) B_{i j}=2344,4 \text { t.o.e } / \mathrm{h} . \\
& P_{1}^{o n}=360 \mathrm{MW}, P_{6}^{o p}=392 \mathrm{MW}, P_{7}^{o p}=600 \mathrm{MW}
\end{aligned}
$$

and from the condition for the balance of active power in the power system

$$
P_{0}^{o p}=1815-360-392-600=463 \mathrm{MW}
$$

Thus, the proposed algorithm for accounting for constraints is distinguished by a simple calculation procedure and with sufficient accuracy for practical purposes.

\section{Conclusion}

1. An algorithm is proposed for taking into account inequalities in the form of inequalities in the optimal planning of short-term modes of power systems under conditions of uncertainty of the initial information.

2. On the basis of computational and experimental studies, it was revealed that the proposed algorithm has a simple computational procedure and sufficient accuracy for practical purposes.

3. The proposed algorithm can be effectively used for optimal planning of short-term modes of power systems, taking into account functional constraints in 
the form of inequalities under conditions of partial uncertainty of the initial information.

\section{References}

1. Automation of dispatch control in electric power systems/ Ed. by Yu.N. Rudenko and V.A.Semenov. M.: Publishing House MPEI, 2000.

2. Fazylov H.F., Nasyrov T.Kh. Calculations of steadystate modes of electric power systems and their optimization. Tashkent: Moliya, 1999.

3. Nasirov T.Kh., Gayibov T.Sh. Theoretical foundations of optimization of power system modes. $\mathrm{T}$.: "Fan va texnologiya", 2014.

4. Methods for optimization of power system modes. V.M. Gornstein, B.P. Miroshnichenko, A.V. Ponomarev and others; Ed. by V.M.Gornstein - M .: Energy, 1981.

5. Arzamastsev D.A. and others. ACS and optimization of power system modes: Textbook for university students / Arzamastsev D.A., Bartolomei P.I., Kholyan A.M. Ed. by D.A. Arzamastsev. M .: Higher. school., 1983.

6. Gayibov T.Sh. Methods and algorithms for power system mode optimization. - T.: Publ. Tashkent State Technical University, 2014.

7. Tulkin Gayibov, Sherxon Latipov, Bakhadir Uzakov. Power System Mode optimization by piecewise-linear approximation of energy characteristics of Power Plants./ Rudenko International Conference "Methodological problems in reliability study of large energy systems" E3S Web of Conference 139, 01086, RSES 2019.2 DOI: https://doi.org/10.1051/e3sconf/201913901086.

8. Valdma M, Keel M, Liik O, Tammoja H. Method of Minimax optimization of Power System Operation. Proc. of IEEE Bologna PowerTech 2003, 23-26 June 2003, Bologna, Italy. Paper 252: p. 1-6.

9. Valdma M, Keel M. and Liik O. Optimization of active power generation in electric power system under incomplete information. Proc. of Tenth Power Systems Computation Conference, 1990, Graz, Austria, p. 1171-1176.

10. T.Sh. Gayibov, Sh.Sh. Latipov. Optimum planning of power modes in conditions of partial uncertainty of background information. Technical science and innovation, 2019. N 2., p. 88-95. 